\title{
Small size metropolitan areas: the case of Patras
}

\author{
V. Pappas \\ Laboratory of Urban and Regional Planning, \\ Department of Architecture, School of Engineering, \\ University of Patras, Greece
}

\begin{abstract}
Patras is the third urban complex in Greece and one of the oldest, having a continuous history of 4,000 years. The modern history of the city is characterized by a rapid and continuous development and transformation, concerning its structure, function and its physiognomy. Although Patras is the first city having an official Master Plan (since 1827), its historical route and evolution is far from rational and planned. The city seems to be unready to face these challenges and does not have the proper infrastructure and planning framework to be able and conscious to form its own development route. The strategic planning alternatives are missing or are absolutely insufficient and the planning process is limited to fragmentary studies, actions, activities and/or initiatives. This work presents and analyses Patras' main characteristics, its evolution, the limitations and problems, in planning process, and forms and documents a proposal concerning a modern planning framework to secure the sustainable development of the whole region. Keywords: sustainable planning, Small size metropolitan areas, Patras, Greece.
\end{abstract}

\section{Introduction}

While the international specialized bibliography uses the term "metropolis" with big frequency, there is not an explicit and widely acceptable definition [1], but it is used with terms that belong in sphere of common perception and acceptance through the abundance of differentiated definitions. Usually the term is reported in the large modern urban complexes that present certain common characteristics from which can be reported, as the most important, the following: a) Their demographic size is reported in certain hundreds thousands residents, b) They have and determine a powerful region and allocate multifunctional character, c) 
They play international role via individual specializations (infrastructures of health, education, trade, transports, etc).

Generally in the last three decades, in the developed countries, they take place a line of economic reformations mainly focused on the sector of services and its appointment as the basic economic activity [2]. This process, as it is obvious, has consequences in the built space, in the land uses and in the whole structure of urban space. Accordingly, this process, affects the whole process of cities' development and evolution, as composite and complicated systems, and, of course, in the way of reading, analyzing and planning of space.

Patras, following the example of most big cities, and after it passed - or at many it continues passing - the phase of deindustrialization, it presents intense rhythms of economic changes. Consequently its function as city - in the wider region and its spatial structure - is oriented in the tertiary sector having characteristics of a small size metropolitan centre [3]. Additionally if we consider its geographical site, the programmed and under construction works in the wider region (the new port, the new national road axis from north to south, the Ionian road, the new bridge Rion-Antirrion, the new railway line, etc), these changes are very rapid and influence intensely the development of building environment, its relation with the adjacent regions, and mainly the quality of environment (natural and build-up) and the quality of life of its residents. "New" replaces "old" with rapid rhythms without any planning frame. All the responsible organizations and services function with out-of-date terms and the way of management and control of operation and development of city becomes a critical affair that requires new terms, conditions and administration environment of operation and planning.

In this complex frame the critical question is the dialogue for the developmental way of city, the planning and monitoring process of this developmental route and its space, as the arena of all these activities, where the consequences in the urban structure and function must specialized and planned for the common affair that is the sustainable development and the quality of living. At the same time it should examined and specialized its role in the wider region as a metropolitan center with international influence.

Critical role in this urban complex plays (apart others) the operation of new permanent junction of canal Rion-Antirrion and the way that influences the wider urban complex, where the administrative policy of bridge, in combination with the way of extension, planning and control of urban space, is nominated as a critical factor for the urban unification and the metropolitan operation of the region.

\section{The new bridge}

The permanent junction of strait Rion-Antirrion with a technical work of continuous operation constitutes a demand of residents and institutions of the region for more than a century. The factors that strengthened and actualized the demand of permanent junction, should be sought in the wider frame of economy, social, and regional evolution, and the development of last three decades, as well as in the "cultural" dimension of developmental requests and objectives. The 
importance of junction, and its role in the basic national road network, was studied in the frame of National Regional Plan and Program of Greece [4]. The junction Rion-Antirrion was considered by the study as "key" on the completion of National Road Network and as an essential element for the connection of Western Greece with Athens and Peloponnese and Western Peloponnese with Western, Central and North Greece.

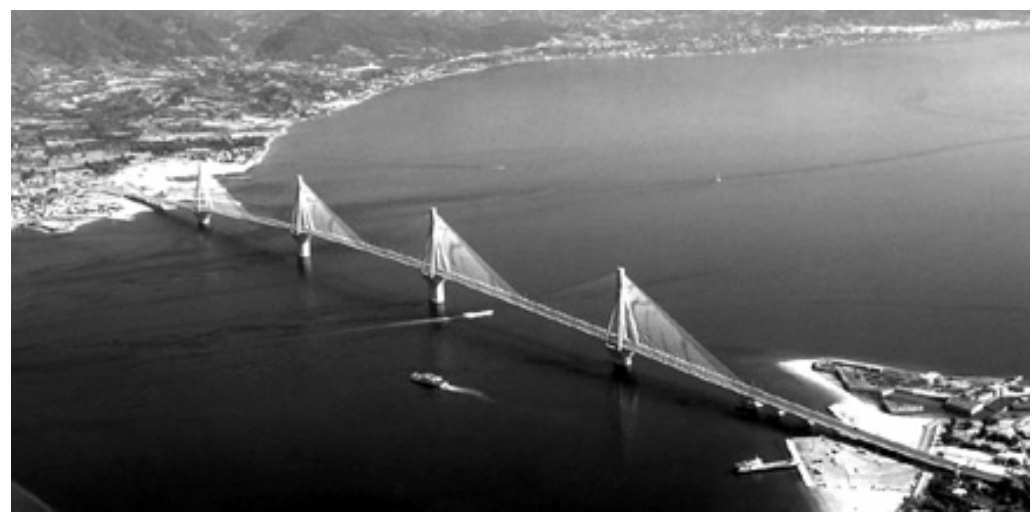

Figure 1: Bridge Rion-Antirrion, aerial view.

Concrete initiatives for discussion and study of possibilities and feasibility of the connection were undertaken in the past. Particularly important should consider the International Congress in the University of Patras in 1978, which the proceedings contain useful information [5]. The proposals covered technical, economical, traffic and development subjects, and present particular interest from the opinion of main problematic of those years. The absence of permanent junction was engaged in all this bibliography, as factor that: a) It negatively affects the exploitation of developmental possibilities of Western Greece, concerning the "privileged" east axis North-South, and decreasing considerably the indicators of investments competitiveness in the region. b) It deters the organization of a main vertical road and transport network that would promote unification processes of regional space of Western Greece. c) It imposes an exceptionally high extended cost in the communication of Westerner continental Greece and Corfu with the Capital and others regions of country, either with the form of economic surcharge, either with the uncertainty and delays in traffic movements.

Therefore the demand of junction was widely adopted, targeting to the lifting of negative repercussions, without however an in depth study of existing relations of dependencies and developmental potentialities of Westerner Greece, and mainly the examination and definition of internal structure of this geographic space and its regional constitution. In conclusion, it should point out that the choice has done and the bridge already functions and therefore the research and study of any potential consequence and prospective gets a new character: a posteriori evaluation and exploitation. 


\section{Patras urban complex}

The urban complex of Patras is constituted, according to the National Statistics Service of Greece (1991), by the next regions: Patras, Aktaio(c), Vrachnaiika(c), Mintilogli(c), Monodendri (c), Ovria(c), Paralia(c), Rion(c), Rogitika(c), and Tsoukaleika(c) [Since 1997, the communities (c) have administratively changed into municipal apartments]. Today, and according to the extents of built space and the existing flows and networks, the wider urban complex tends to include and the Municipalities of Antirrion and Navpactos (both in the north side of strait).

The relation of interdependence Patras - Rion and the other communities is undeniable. The other two Municipalities, Antirrion and Navpactos, present today a relative lifting of a pre-existed "contacts-preservation" (This pre-existed "contacts-preservation" was based mainly to the high cost of passing the canal via ferries). Resent unofficial measurements show that the increase of vehicles traffics, via the bridge, has been increased in a percentage of 20-25\%. Undeniably and in any case, Patras constitutes a first degree centre of services for the entire region of Western Greece.

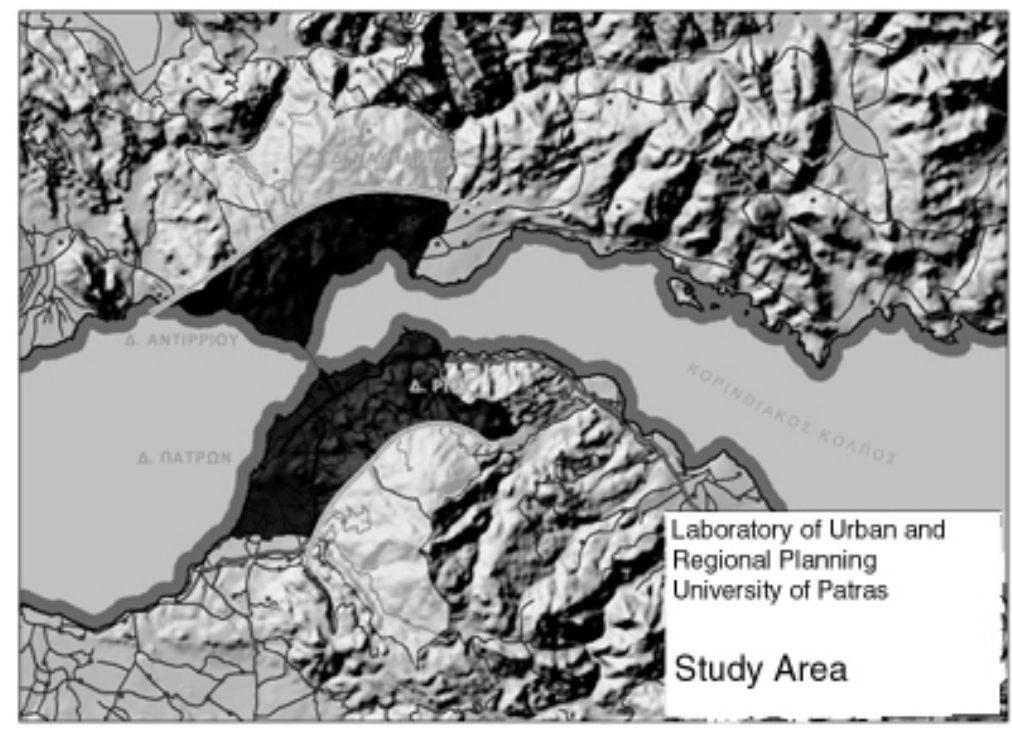

Figure 2: The region of junction.

At the same time the process of urban diffusion and unification has been intensified, but without a clear explanation if this phenomenon is based - mainly in the south part of canal - in the operation of junction or it takes place under the powerful effect of other factors (e.g. bypass road of Patras).

According to the last national population census (2001), the wider urban complex has approx. 200.000 residents which appear to be the most retained estimation. The total extent is $434 \mathrm{~km}^{2}$., from which the $110 \mathrm{~km}^{2}$. constitute the wider urban region around the bridge (the less populated regions and the mountainous areas of Municipalities are not included). 
During the last thirty years the region presents a continuous demographic increase as it appears in the following graph. More specifically in the graph, the demographic evolution is presented in weighed prices (population 1971 =1) in order to give the bigger relative demographic increase, which is presented in the Municipality of Rion.

Additionally, the local municipal services of Antirrion have a strong argument that the official census data give an underestimate icon for the population size of settlement. At their opinion, the residents of Antirrion are considerably more and this underestimation is based to the known phenomenon of, during the census, a lot of residents move to their native rural areas (The figures, which document this opinion, are based to the water consumption meters, the telephone bills, and the households' electricity consumption within the municipality). Respectively the same positive demographic evolution presents the wider region of Western Greece.

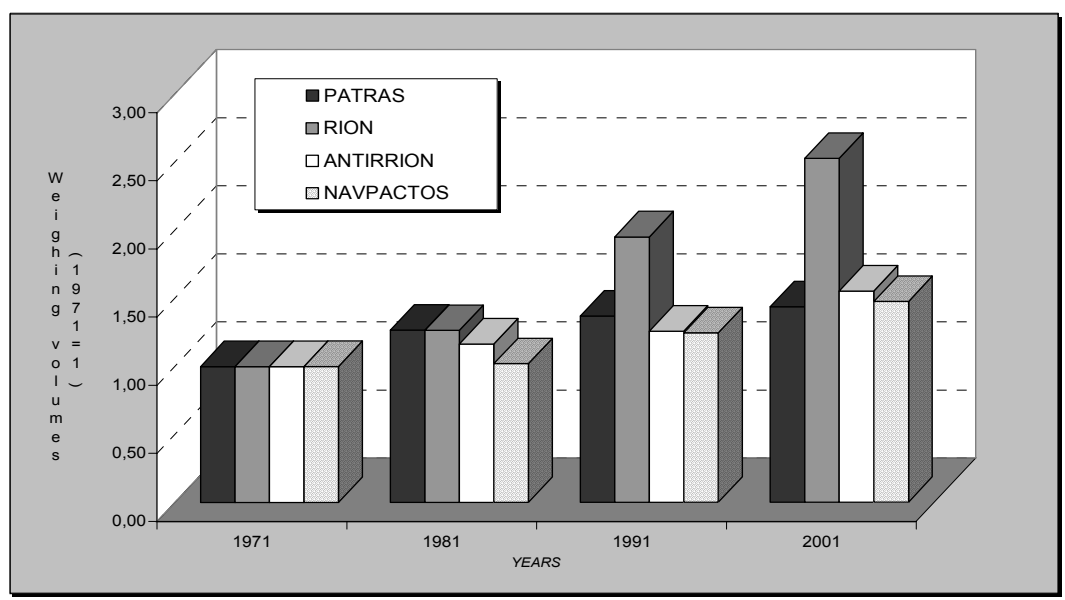

Figure 3: Demographic evolution in the study area.

\subsection{Main characteristics of urban complex}

Today, the main characteristics of urban complex are as follows.

(a) It has a single-centre. The unique centre of entire complex is the central core of Patras, and it is delimited, more or less, by the roads Kanakari, Aratou, Corinthu, Karolou, Othonos-Amalias and Trion Navarchon. In this area are located the bigger percentage of commercial activities, central administrative and economic functions, cultural, and also recreation facilities and activities.

(b) It is characterized by a relatively homogeneity on built-up environment and growth based on "general residence" land use, in which are interfered small areas of other character. Moreover, the wider urban complex has an intense linearity parallel to the coastal line of Patraikos-Corinthian gulf (This linearity should not be confused with the bilinear character of extent of city of Patras: North - South and West-South-eastern). 
(c) The southern area, that is to say the Municipalities Patras and Rion, is crossed by the National Road axis Athens - Korinthos - Patras - Pyrgos, where already exists the bypass road of Patras, which begins from Rio, almost immediately afterwards the tolls, and leads to the south-western exit of city. A direct result of its operation is to strength the tendencies of built-up extension of city to the southerner - south-eastern.

The operation of bypass road has eased the traffic in the centre of Patras, from the going-through traffic (north to south), but remains as one important question the absorption of traffic caused by the port, as the connecting roads, to the bypass road, are still missing.

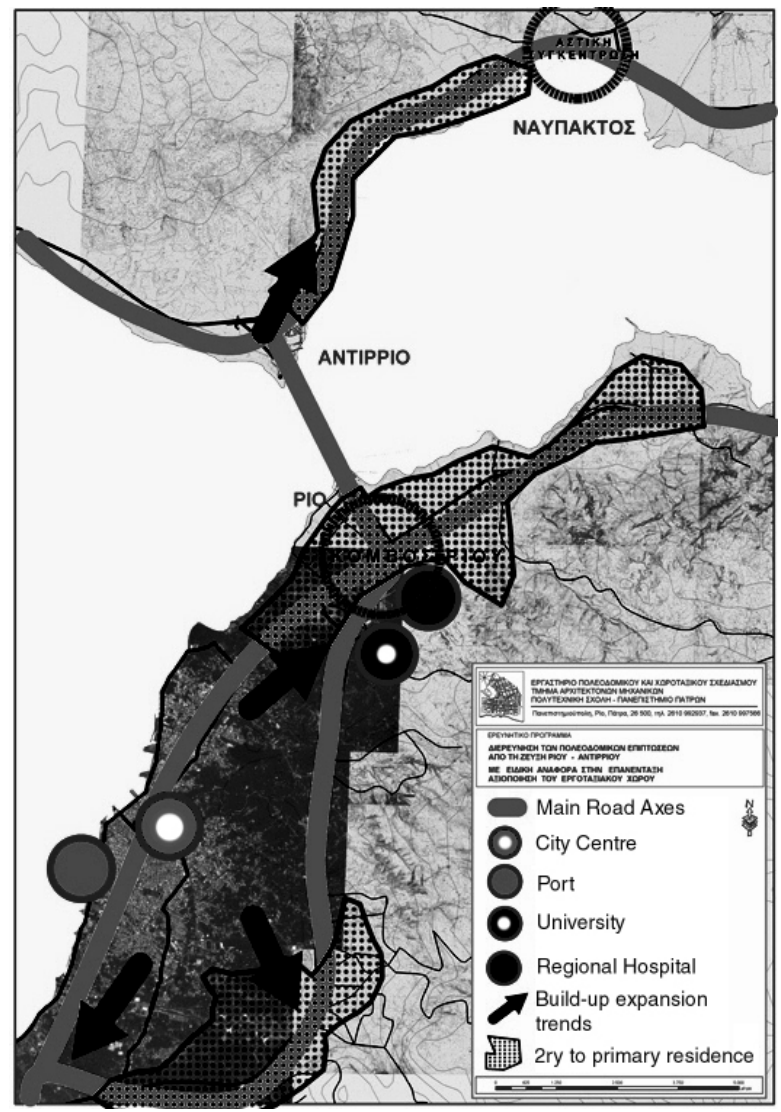

Figure 4: Built-up growth and tendencies.

(d) The urban complex includes three inter-regional poles-activities: the port, the University campus and the other academic institutions, the Regional Hospital.

(e) The northern area, Antirrion-Navpactos, is characterized by a corresponding linear development with a parallel traffic, the National Road Agrinio - Antirrio Navpactos - Itea. Even if the tendencies of built-up expansion, in the northern side, have not been expressed yet in intense degree, it is estimated that the 
increase of degree of accessibility, with the operation of bridge and the bypass road of Navpactos, will cause the same phenomenon that was observed in the southern side in the axis of Patras - Rion: an intensive linear build-up expansion of the city. Additionally a minor importance commercial centre exists in Navpactos.

(f) The two areas, with their corresponding parallel traffic axes, are connected with the bridge. With the beginning of operation of bridge, the two areas, "south" and "north", have come closer than before the junction. A characteristic statement is that the distance Rio - Navpactos is covered anymore within 15 minutes, while the distance from the centre of Patras (Georgiou square) Antirrio is $12 \mathrm{~km}$ and is covered in 15 minutes on average. The calculation of these time-distances is based on modern techniques of Geographic Information Systems as it is shown on the following maps.

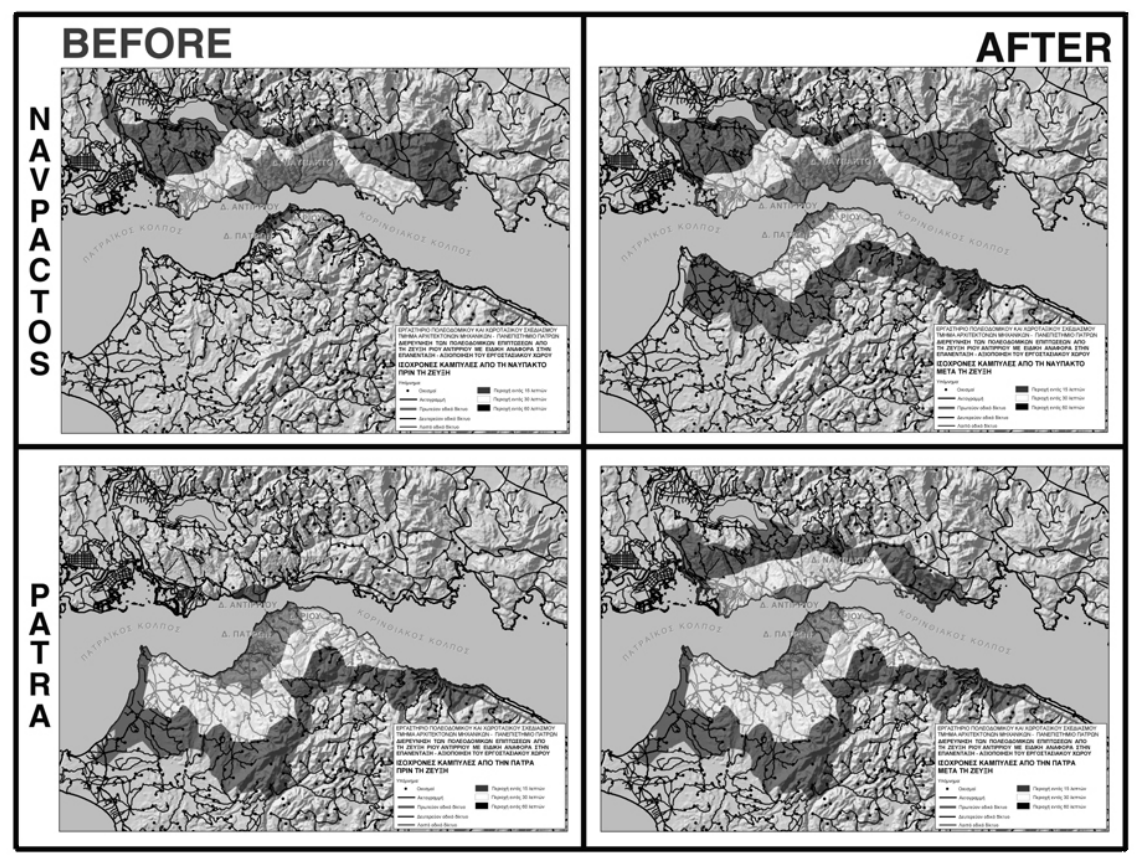

Figure 5: Equal-time zones (within 15, 30 and 60 minutes).

The systematic analysis of urban complex structure illustrates the following [6].

(a) The urban complex is already in a process of "extension and intensive growth of urban web", which will be continuously intensified for the next years. The term "extension and intensive growth of urban web" is reported in the systematic enlargement and diffusion of urban density and also in the continuous transformation of suburban areas into urban.

This phenomenon, in some degree, is in effect in all urban complexes under transition. In previous time-periods, the continuous extension of urban web was 
based only (or mainly) in the increase of urban population. However, the phenomenon in which we were reported has explicit qualitative differences and it is not related immediately with the increase of urban population but with the city dynamics (increase of activities, land use changes, land values, land investments, planning parameters, etc.). The figure 6 reinforces this remark and illustrates the population and area evolution of the official Master Plan of the city (weighed values: area and population at the year $1858=1$ ).

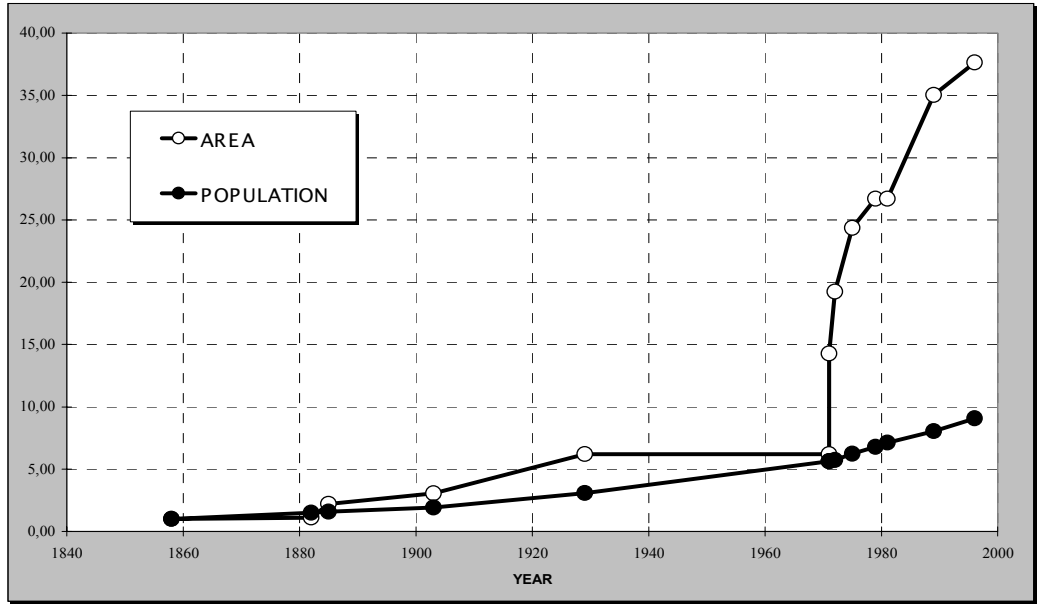

Figure 6: Population and area evolution of Patras.

(b) The extension and intensive growth of urban web, take place in all directions, but in a different way for each land use.

(c) Corresponding to the extension of residence to north-eastern, the industrial and the heavy commercial (large supermarkets, etc.) uses present intensive movements to south-western where exist a lot of big abandoned industrial properties and take place big private investments, mainly for entertainment, and the initiatives of Municipality (formation and renovation of existing installations for the needs of "Patras: cultural capital of Europe, 2006"). But the most important of all is the planned, and already under-construction, new port of Patras in the same area (Akti Dymaion) with all relative activities, infrastructures and connections (new railroad, new connecting roads, etc.).

(d) A third direction of urban expansion, is to south-eastern, on the Kalavriton road. The whole region is characterized already by intensive land uses (Old hospital, Technological Institute, National stadium, large supermarkets, etc.). These tendencies are already present with the operation of bypass road, and are in close relation with the land uses of new port (under construction).

(e) The operation of bypass road with the operation of Bridge Rion - Antirrion have changed the existing model of city's accessibility. It is known that big road axes create enormous urban developmental powers and tractions. Particularly in the exits of traffic systems (as these two cases are) the centripetal forces are exceptionally powerful. This fact gives a particular importance in the region of 
Rion, as, in this area, the two endings of bridge and bypass road are come together in a unique point (fig. 4). It is absolutely certain, that the next years, this point will become one of the more dynamic nodes of wider urban complex, where already has start to appear this character, as a simple measurement of traffic volumes documents.

(f) The process of urbanization has already begun in the zone "Antirrion Navpactos", based on the increased accessibility from the centre of urban complex, and also due to the promptly operation of new bypass road of Navpactos.

Summarizing all the above, and as it was expected, it is more than obvious the nodal role of operation of bridge in the prospect of urban completion and metropolitan operation of the whole urban complex Patras - Rion - Antirrion Navpaktos. And precisely in this prospect, the operation of two regions, north and south of the bridge, Rion - Antirrion, play the most important role, where an integrated planning in strategic level, but also in the level of urban interventions, constitutes a crucial element. It is critical to strength the function and the character of urban complex with all the necessary actions and plans in order to find a new role and to face challenges not only in the national, but even in the European context.

\section{Summary proposals}

As a synthetic conclusion of the previous summary analysis of urban pattern and structure of the wider urban complex Patras - Rion - Antirrion - Navpactos, are mentioned the following proposals, as structural components of a Master plan for the whole area, something that is absolutely essential and it has to be prepared immediately.

(1) To plan the development of three new urban centres, in combination of the existing one (Patras), and with their cooperation to achieve better structure and operation of wider urban complex. If we suppose that Patras constitutes an urban centre of first level, is proposed the development of two centres of second degree, in Rio and Navpactos, and a centre of third degree, in Antirrion. The precise composition and planning of potential main activities of these centres is objective of proposed Master Plan.

(2) The proposed Master Plan has to define exactly the character of each pixel in the urban mosaic. It is proposed to intensify the existing residential character across the coasts, northern and southern the bridge. Respectively, the industrial uses and activities should be allocated in specific and well defined areas.

(3) It is obligatory to constitute and organize a traffic model for the whole urban complex. It is necessary to define and organize decisively three levels of traffic flows: inter-local network (new national road to Athens, Bridge, bypass road of Patras), main road network (old national road to Athens, main urban axes, connecting roads, coastal roads) and the local road network.

(4) In combination with the previous proposal, the substantial improvement of the urban public transport network is more than crucial. That would server, with unified logic and operation, the entire urban complex from Navpactos to the southern suburbs of Patras. The development of a transport network based on 
public transport means, can improve not only the daily function of urban complex, but also to contribute to the improvement of the whole urban structure and to discourage the use of private car. It is proposed to examine, as a long-term policy, the construction of tram-line for the wider region. The construction of the proposed tram-line can be based to the existing railway infrastructure.

Summarizing, the whole region in the last years, is under the catalytic influence of big technical interventions (constructed and programmed) as well as from the structural and functional evolution of city of Patras and its suburban areas and adjacent Municipalities. These rapid changes take place - mainly without any concrete coordinative or planning framework (at least in local level) and only fragmentary studies exist with the visible danger to become, these studies, total or partial obsolete.

More specifically, is not feasible for any planning process to be limited in the administrative boundaries of each Municipality, as it is in our case, even if this is in consistent with the existing institutional/legislative framework. The urban influence and function and the suburban areas are extended much more by any administrative boundaries and need an integrated planning process. However this type of planning requires mainly political will and social approval in all levels (national, regional and local). Actually, the lack of an integrated Master plan, for the entire region, limits the effectiveness of any planning process, via individual studies, and raises a lot of questions for the compatibility of these studies.

In conclusion, if the spatial planning, not simply presupposes, but substantially constitutes political process of conflicts, choices and changes, it is obvious that this process must be a socially controlled and politically determined process. And in addition, because this process constitutes a continuous dialectic relation cannot be exhausted in a temporally determined and fragmented onetrack studies, but is required a modern frame of planning and the proper infrastructure to secure a continuous planning and monitoring process.

\section{References (all references are written in Greek)}

[1] Aggelidis Minas, "Land-planning and sustainable development", Symmetry Publications, Athens 2000

[2] Oikonomou D., Getimis P., "The international role of Athens", University of Thessaly publications, Volos 2001

[3] cf. the Doxiadis scale of territorial units, ph. Ekistics international journal, "The anthropocosmos model", pp. 226, volume 56, number 338/389, Sept ./Oct. - Nov./Dec. 1989

[4] Doxiadis Office, "National Regional Plan and Program of Greece", report No 19, Volume 6, Networks of Transports, Ministry of Coordination and Programming, Athens, 1980

[5] Goudas K. (editor), "Junction Rion - Antirrion", Proceedings, International Congress, University of Patras, 1978

[6] Polydorides N., Pappas V., Aesopos Y., Patrones Y., "Definition of urban and regional consequences from Rion-Antirrion junction. Special report on utilization and re-accession of bridge worksite", Research project, Department of Architecture, University of Patras, Patras, 2003 